\section{A Narrowly Endemic Dirca from Mexico Outperforms Its Broadly Distributed Congener in the Upper Midwest}

\author{
Kelly D. Norris and William R. Graves ${ }^{1}$ \\ Department of Horticulture, Iowa State University, Ames, IA 50011-1100
}

Additional index words. Thymelaeaceae, leatherwood, native plants, shrub, provenance, common-garden experiment

\begin{abstract}
Shrubs in the genus Dirca are rarely used in landscaping despite their shade tolerance and aesthetic qualities. A trial of 81 plants, 27 of each of three species, was established in 2007 in USDA hardiness zone 5a to evaluate survival and growth. After four winters, survival of Dirca mexicana $(89 \%)$ was greater than survival of Dirca palustris from Florida (44\%) and Dirca occidentalis (41\%). Survival of Dirca palustris from Ontario, Canada, was intermediate (56\%), but annual stem extension was only $60 \%$ that of Dirca mexicana and Dirca palustris from Florida. Surviving plants of Dirca mexicana and Dirca palustris from Ontario showed minimal winter injury, but tips of some stems of Dirca palustris from Florida and Dirca occidentalis were killed. Our data on survival, winter injury, plant health, and stem extension of the California-endemic Dirca occidentalis suggest it will be especially challenging to identify genotypes adapted for use in the Upper Midwest. In contrast, we conclude that another narrowly endemic species, Dirca mexicana, has potential as a new shrub for horticulture. Additionally, our results provide evidence for variation in cold-hardiness and annual stem extension of Dirca palustris. Although over half of plants from Florida had died after the first two winters, no additional mortality occurred over remaining years, and survivors were more vigorous than plants from Ontario. This suggests that exploitable variation in coldhardiness and vigor exists among and within populations of this broadly distributed species.
\end{abstract}

Many ornamental plants indigenous to North America remain obscure in cultivation despite public interest in native taxa (Brzuszek and Harkess, 2009; McMahan, 2006). The North American genus Dirca L. comprises shrubs called leatherwoods. Despite a long history of favorable descriptions (Anderson, 1933; Buffin, 2005; Del Tredici, 1984; Kirkegaard, 1912), Dirca spp. remain rare in commerce and underused as landscape plants. This likely is the result of difficulty reproducing plants asexually and slow growth of seedlings. Showing that some species within the genus grow unusually rapidly, or locating populations within species that represent sources of unusually vigorous germplasm, could lead to broader use of Dirca.

Dirca palustris L. occurs in localized populations across the eastern one-third of North America from Nova Scotia, New Brunswick, and Ontario, west to North Dakota, south to Oklahoma and Louisiana, and east to northern Florida (Nevling, 1964; Peterson et al., 2009). Despite its broad distribution, D. palustris is uncommon in most of its range and is deemed

Received for publication 11 June 2012. Accepted for publication 20 Aug. 2012.

We thank James Schrader, Bryan Peterson, and Matt Helgeson for assistance.

${ }^{1}$ To whom reprint requests should be addressed; e-mail graves@iastate.edu. endangered in Florida and threatened in Maryland (Wunderlin and Hansen, 2008). Shrubs typically occur in understories of rich, mesic forests, often on north-facing slopes above waterways (Williams, 2004). Dirca occidentalis Gray is found in discrete habitats near the San Francisco Bay in California, where it is adapted to a Mediterranean climate in USDA hardiness zone 9 and accrues minimal cold-hardiness (Graves et al., 2006). Long-term survival of a plant on the campus of Iowa State University (USDA hardiness zone $5 \mathrm{a}$ ) indicates the species can be used in areas with harsh winters, but formal tests of this potential have not been conducted. A single population of Dirca mexicana Nesom and Mayfield has been reported at an elevation of $\approx 1800 \mathrm{~m}$ in the Sierra Madre Oriental, Tamaulipas, Mexico (Graves, 2008; Nesom and Mayfield, 1995).

All Dirca spp. share traits valued by horticulturists. Their nearly exclusive natural occurrence in forest understories portends shade tolerance in cultivation, and all species bear yellow flowers. Inflorescences usually comprise three flowers that appear when few other temperate shrubs bloom. Flowering time of D. palustris varies with latitude from February (Florida) to May (northern-most populations). Dirca occidentalis blooms after late summer and fall rains that end the Mediterranean dry season and break the summer dormancy of the species. Flowers are prev- alent as early as October and as late as March with anthesis of most plants in January (Graves, 2006). In its native habitat, D. mexicana blooms in March (Graves, 2008). Later each growing season, shrubs of all species display golden yellow leaves as they enter dormancy before winter or, for $D$. occidentalis, as the dry season ensues. Another notable trait is the unusually arborescent form of mature specimens (Dirr, 1998; Esson, 1949). Little is known about how the species respond to various edaphic conditions, but reports concerning soils that support natural populations suggest that Dirca spp. are adapted to a range of soil types and $\mathrm{pH}$ (Clark, 1971; Cooperrider, 1962; Del Tredici, 1984; Peterson and Graves, 2009).

Protocols for germinating seeds of Dirca spp. have been reported (Schrader and Graves, 2005), and we routinely achieve high germination rates by collecting fruits from April through June and cold-stratifying seeds the next winter. Because Dirca spp. typically grow slowly (Dirr, 1998; Esson, 1949), producers and consumers could benefit from knowledge of interspecific and intraspecific variation in growth rates among members of the genus In addition, research is needed to examine provenance differences in hardiness, plant vigor, and other traits among the broadly distributed $D$. palustris and to assess potential for using $D$. occidentalis and $D$. mexicana outside of the small areas where they are endemic. We initiated a common-garden experiment to evaluate plants in USDA hardiness zone 5a. Our specific objective was to document survival, winter injury, annual stem extension, and apparent health of the three species over four growing seasons. Seedlings of $D$. palustris from both a northern and southern population were studied to examine intraspecific variation.

\section{Materials and Methods}

Sources of germplasm. Drupes on naturally occurring plants were collected in 2005 from D. palustris near Thunder Bay, Ontario, Canada, and in Liberty County, FL; from D. mexicana in Tamaulipas, Mexico (Graves, 2008; Nesom and Mayfield, 1995); and from D. occidentalis in San Mateo County, CA. Drupes were sown in flats and subjected to warm and cold stratification, which led to germination of seeds in April of 2006. Seedlings were potted in a soilless medium and cultured in a greenhouse until they were installed outdoors in late 2007.

Establishment of the experiment. A commongarden plot was established in 2007 in Ames, IA

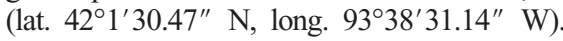
The site, which was chosen for its similarity to sites that support wild populations of all Dirca spp., was within the understory of a woodland, $\approx 10 \mathrm{~m}$ upslope from a creek. Overstory vegetation included species of Acer L., Fraxinus L., Juglans L., and Ulmus L. Invasive shrubs such as Lonicera tatarica L. were removed, but groundcovers and woodland ephemerals were retained. The sandy loam soil had a mean $\mathrm{pH}$ of 7.6 and mean organic matter content of $11.4 \%$. Mean 
photosynthetically active radiation near solar noon on cloud-free days was 45 to 150 $\mu \mathrm{mol} \cdot \mathrm{m}^{-2} \cdot \mathrm{s}^{-1}$.

Plants were installed on 24 Oct. 2007, when they were 18 months old and completing their second growing season. Twenty-seven plants of each species (81 total) were arranged randomly $0.5 \mathrm{~m}$ apart in rows separated by $1 \mathrm{~m}$. For D. palustris, 18 plants were from Florida, and nine were from Ontario. Each newly installed plant was irrigated with $\approx 1.5 \mathrm{~L}$ of water from the nearby creek, and the soil surface in a $15-\mathrm{cm}$ radius around each plant was covered with chipped wood and bark mulch in a layer $\approx 5 \mathrm{~cm}$ deep. Plants were not irrigated again nor was fertilizer applied. Air temperature was logged with three iButton Data Loggers (Maxim Integrated Products, Sunnyvale, CA), and data on annual precipitation were obtained from a weather station $4.8 \mathrm{~km}$ away. The minimum temperature recorded each winter, usually in January, was $-26,-32,-27.5$, and $-23{ }^{\circ} \mathrm{C}$ in $2008,2009,2010$, and 2011 , respectively (Fig. 1). Mean daily maxima from 1 May through 31 Aug. were similar throughout the study and ranged from a low of $31^{\circ} \mathrm{C}$ in 2009 to a high of $33^{\circ} \mathrm{C}$ in 2010 . Annual precipitation from 1 Nov. through 31 Oct. ranged from $96.3 \mathrm{~cm}$ in 2008-09 to $136.9 \mathrm{~cm}$ in 2009-10.

Data collection and analysis. Data were collected twice annually from 2008 to 2011. Each 1 May, plant survival and the extent of stem injury of living plants were rated. No injury led to a rating of 3 . Plants with stems that were dead from the apex basipetal to a location less than $50 \%$ of the length of the shoot system were rated 2 , whereas living plants with more extensive injury were rated 1 . Each 1 July, the health of each plant was rated, and the length of the longest stem that extended during the single flush of annual shoot growth characteristic of Dirca spp. was measured. To rate health, plants that appeared to be in excellent condition were rated 3 , whereas plants that displayed foliar maladies such as chlorosis, herbivory, or physical distortion were rated either 2 or 1 if the symptoms were mild to moderate or severe, respectively. Analysis of variance was conducted within years with the Statistical Analysis System 9.1.3 (SAS Institute Inc., 2002), and means were separated by the Tukey-Kramer honestly significant difference test. We analyzed plants from the two widely separated provenances of $D$. palustris as different treatments to assess intraspecific variation.

\section{Results}

Survival of D. mexicana decreased to $89 \%$ after two winters but remained stable from 2009 to 2011 (Fig. 2). After four winters, survival of D. occidentalis and D. palustris from Florida had decreased to $41 \%$ and $44 \%$, respectively, whereas survival of $D$. palustris from Ontario was 56\% (Fig. 2). Although mean separation statistics for plant survival are displayed only for 2011 in Figure 2, survival of D. palustris from Florida was less than that of D. mexicana all four years and was less than survival of $D$. palustris from Ontario in 2008. Survival of $D$. occidentalis was lower than

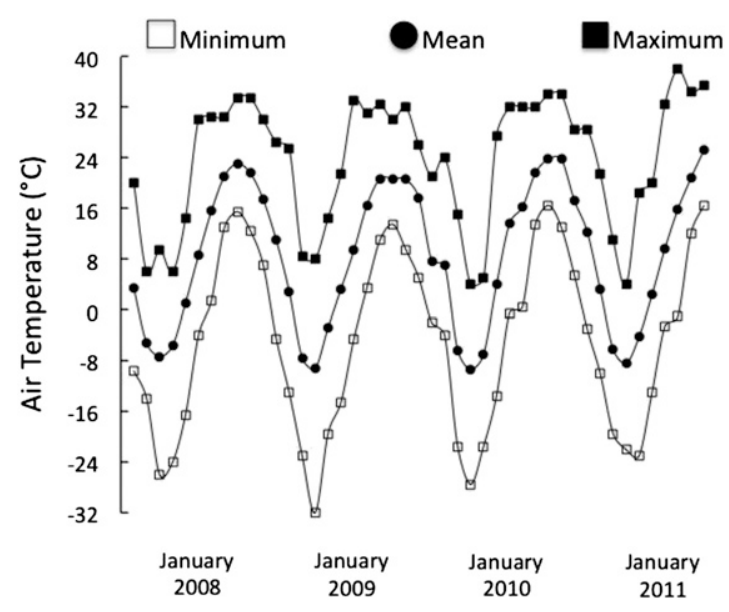

Fig. 1. Air temperature at the common-garden site in Ames, IA, where a trial of Dirca spp. was conducted. Means are shown for each month and were determined from data collected once per hour. The single highest and lowest temperatures recorded during each month also are shown.
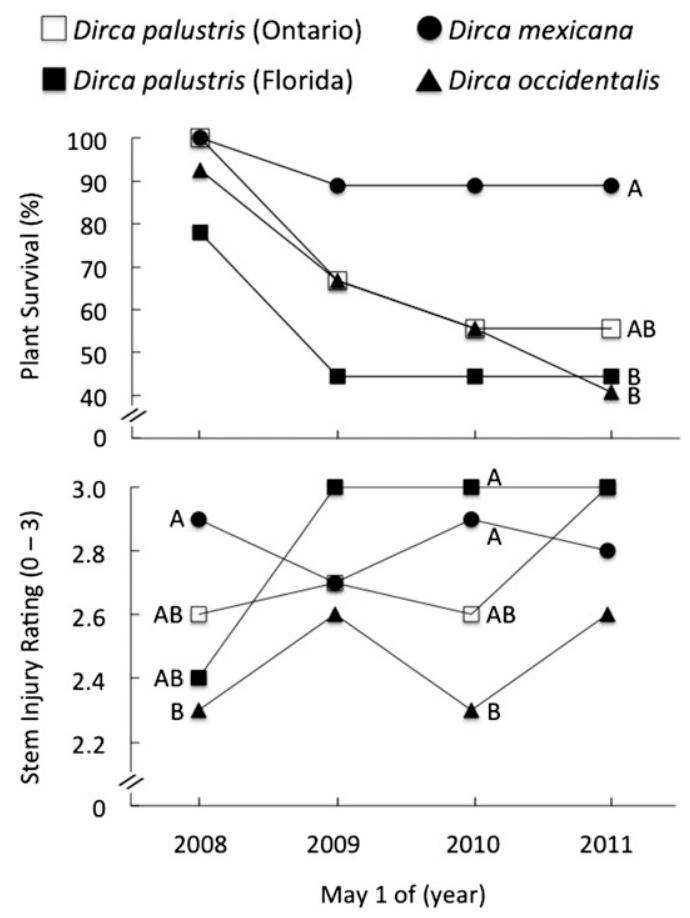

Fig. 2. Survival and stem injury of D. mexicana, D. occidentalis, and D. palustris from Ontario and Florida on 1 May of four years in a common-garden plot in Ames, IA. Stem injury was rated subjectively. Plants with no and complete stem death were rated 3 and 0 , respectively. Plants with stems that were dead from the apex basipetal to a location less than $50 \%$ of the length of the shoot system were rated 2 , whereas living plants with more extensive injury were rated 1. Values are based on 27 plants of each species. For D. palustris, 18 and nine plants were from Florida and Ontario, respectively. Means were separated with the Tukey-Kramer honestly significant difference test. For plant survival, separations are shown only for data collected on the last 1 May of the experiment. For stem injury, separations are shown for the two years when means differed.

that of D. mexicana in 2010 and 2011. Among surviving plants, $D$. occidentalis showed more stem injury than D. mexicana in 2008 and more injury than $D$. mexicana and $D$. palustris from Florida in 2010 (Fig. 2); no differences in injury were evident in 2009 and 2011.

In 2009 through 2011, mean length of the longest newly extended stem per plant generally was greater for $D$. mexicana and $D$. palustris from Florida than for the other plants; however, in 2011, D. palustris from the two provenances did not differ (Fig. 3). Health ratings tended to increase over time as plants in comparatively poor health died and were not subsequently rated (Fig. 3). Among plants alive in 2011, D. occidentalis were in poorer health than plants of D. mexicana and D. palustris from Florida (Fig. 3). Health among plants differed most in 2008, when many plants that later died were alive (Fig. 2). Although mean separations for health ratings in 2008 are not depicted in Figure 3, statistical tests showed the health of 


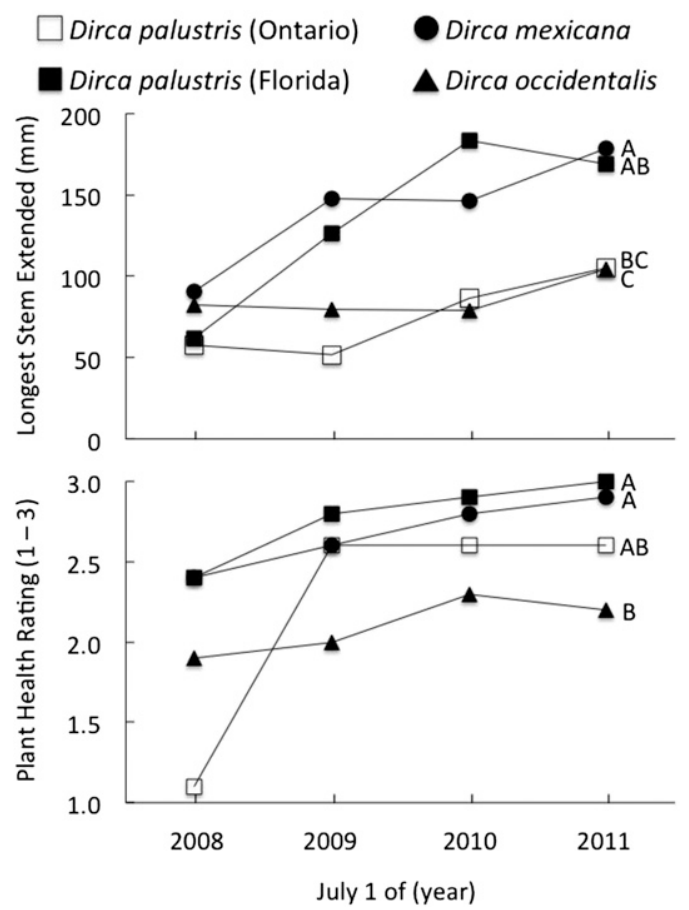

Fig. 3. Length of the longest newly extended stem each year and mean health rating D. mexicana, D. occidentalis, and D. palustris from Ontario and Florida on 1 July of four years in a common-garden plot in Ames, IA. Plants that had died were not considered; values are means of five to 25 . Health was rated subjectively. Plants that appeared to be in excellent condition were rated 3, whereas plants that displayed foliar maladies such as chlorosis, herbivory, or physical distortion were rated either 2 or 1 if the symptoms were mild to moderate or severe, respectively. Means were separated with the TukeyKramer honestly significant difference test, and results are depicted for 2011. In 2008, there were no differences among means for the longest stem extended. In 2009 and 2010, length of the longest stem of D. mexicana and D. palustris from Florida was greater than that of D. occidentalis and D. palustris from Ontario. For plant health, mean-separation results were similar for the final three years, but, in 2008, the mean for D. palustris from Ontario was lower than the other three means.

D. palustris from Ontario was poorer than that of D. mexicana, D. occidentalis, and D. palustris from Florida.

\section{Discussion}

Data from this experiment support important horticultural conclusions about $D$. palustris, which has been introduced to and promoted for horticulture and about two rare endemic congeners that are absent or rare in commerce. First, landscape performance of the broadly distributed $D$. palustris will differ based on the provenance of origin of the plant material. Second, individual plants of D. occidentalis can survive outside of the small niche in California where they are native, but, as a species, D. occidentalis is poorly suited to the conditions imposed on it in the Upper Midwest. In contrast, D. mexicana performs well in the Upper Midwest and may have potential for broad use in horticulture.

The two populations of $D$. palustris we sampled for seeds are $\approx 2500 \mathrm{~km}$ apart, and the appearance of the resulting plants differed as did their responses to our trial site. Although we did not compare morphology formally, leaves of plants from Ontario appeared smaller than is typical for the species and were pale green and sometimes distorted by bullate surfaces, whereas leaves of plants from Florida were comparatively large, dark green, and free of imperfections. Mean extension of the longest newly formed stem of plants from Florida was more than twice that of plants from Ontario in 2009 and 2010, which is representative of our observation that plants from Florida were especially vigorous. Differences in survival between $D$. palustris from the two provenances during 2009 through 2011 were not significant. However, the $78 \%$ survival of plants from Florida in 2008 (Fig. 2), after a winter when the minimum temperature was $-26{ }^{\circ} \mathrm{C}$ (Fig. 1), was less than the $100 \%$ survival of plants from Ontario. The plants from which seeds were obtained in Florida occur in USDA hardiness zone $8 \mathrm{~b}$, where mean annual minima are -6.7 to $-9.4{ }^{\circ} \mathrm{C}$. In contrast, seeds from Ontario were from plants in zone $3 \mathrm{a}$, where minima are -37.3 to $-39.9^{\circ} \mathrm{C}$. Based on survival after four winters (Fig. 2), during which plants were exposed to air as cold as $-32{ }^{\circ} \mathrm{C}$ (Fig. 1), plants from Florida may vary in cold-hardiness potential. A minority of seedlings from that provenance may be capable of long-term survival where winters are as harsh as those in zone 5 , where mean annual minima are -23.4 to $-28.8^{\circ} \mathrm{C}$.

Low temperatures may not have been solely responsible for the mortality we observed among plants from Florida. Nearly $50 \%$ of plants from Ontario, which should be adapted to temperatures colder than those at our trial site, died after three winters (Fig. 2), and stem injury of $D$. palustris from the two provenances did not differ after any of the four winters (Fig. 2). Direct tests of midwinter plant hardiness, fall acclimation, and vernal deacclimation would help to clarify the extent to which low temperatures led to the mortality of $D$. palustris we observed. The unknown factor(s) that led to the death of plants from Ontario might also have caused plants from Florida to perish. Shrubs in another genus in the Thymelaeaceae, Daphne L., die suddenly in cultivation, reportedly as a result of a pathogen (Noshad et al., 2007), but no reports of such a problem have been noted for Dirca spp. Likewise, little is known about microsymbionts that associate with Dirca spp. and whether biological or physical properties of the soil at our trial site might have contributed to plant mortality.

Although not quantified, we observed that D. palustris from Florida had larger leaves with more distinctly acute tips compared with plants of that species from Ontario. This, along with provenance differences in vigor and survival after the first winter, build on two previous reports of intraspecific variation among D. palustris (Peterson and Graves, 2009; Peterson et al., 2011) and other broadly distributed woody species (Repo et al., 2000; Weng and Parker, 2008). More extensive comparisons of $D$. palustris from its numerous populations are needed to document the extent of variation in the species for growth rate and numerous ornamental traits. These include fall leaf color, which can be bright, uniform yellow. We observed that leaves of our plants from Ontario senesced during fall weeks earlier than leaves on plants from Florida, which often remained green until they abscised. Identifying sources of genotypes that grow faster than is typical of the species, like the population we sampled in Florida, is useful for horticultural commerce, but evaluations are needed to determine where selected genotypes can survive and express all of their ornamental traits. There is no evidence that the size of individual flowers or the density of flowers of $D$. palustris varies significantly (Peterson et al., 2011), but the cold-hardiness of flower buds from different provenances remains unknown because the plants we studied remained juvenile during our trial.

The two rare species responded differently to conditions at the trial site. Dirca occidentalis is endemic to sites within hardiness zone $9 \mathrm{a}$ in six counties near the San Francisco Bay (Graves, 2006), $\approx 2900 \mathrm{~km}$ west of where trial was conduced. Graves et al. (2006) found that stems of plants in their native habitat did not accrue resistance to low temperature during winter substantially beyond that necessary to persist in zone 9a. However, these authors noted that a plant installed in the Upper Midwest had sustained multiple harsh winters there and suggested that the extent of hardiness accrual may depend on the environmental cues to which plants are exposed. Our results substantiate the claim that plants of $D$. occidentalis can persist in the Upper Midwest, although most plants in our trial were not alive after four winters. In addition, the longest newly formed stem was 
shorter, and the mean health rating of surviving plants was lower, for $D$. occidentalis than for D. palustris from Florida and D. mexicana in 2009 through 2011 (Fig. 3). Notwithstanding the fact that expression of adaptive differences within species may become more pronounced as life-history stages progress, particularly in long-lived species (O'Brien and Krauss, 2010), we conclude D. occidentalis is less suitable for use in the Upper Midwest than $D$. palustris from at least certain provenances.

Our findings for $D$. occidentalis contrast those for the rarer endemic, D. mexicana. The single reported population of $D$. mexicana is $\approx 2200 \mathrm{~km}$ southwest of the site of our experiment. Although the lowest temperature recorded among indigenous $D$. mexicana over three winters was $-2{ }^{\circ} \mathrm{C}$ (Graves, 2008), a higher percentage of $D$. mexicana than $D$. palustris from Florida and D. occidentalis survived four winters in our trial (Fig. 2), stems extended comparatively well (Fig. 3), and plants appeared healthy (Fig. 3). By the growing season of 2011, the surviving plants of D. mexicana $(89 \%)$ and $D$. palustris from Florida (56\%) were easily distinguished from D. palustris from Ontario and D. occidentalis as a result of their larger size and healthy, dark green foliage. We noted but did not quantify subtle morphological differences between D. palustris from Florida and D. mexicana. Dirca mexicana appeared to have especially blunt leaf tips and narrow angles of branch attachment, leading to a more upright plant form, than D. palustris from Florida. Further evaluations and comparisons of these promising genotypes in other locations are warranted.

\section{Literature Cited}

Anderson, E. 1933. Leatherwood (Dirca palustris). Arnold Arb. Bull. 1:25-27.
Brzuszek, R.F. and R.L. Harkess. 2009. Green industry survey of native plant marketing in the southeastern United States. HortTechnology 19:168-172.

Buffin, M.W. 2005. Winter-flowering shrubs. Timber Press, Portland, OR.

Clark, R.C. 1971. The woody plants of Alabama. Ann. Mo. Bot. Gard. 58:99-242.

Cooperrider, T.S. 1962. The flora of north-facing slopes compared to that of the surrounding area in eastern Iowa. Amer. Midl. Nat. 67: 368-372.

Del Tredici, P. 1984. Propagating leatherwood: A lesson in humility. Arnoldia 44:20-24.

Dirr, M.A. 1998. Manual of woody landscape plants: Their identification, ornamental characteristics, propagation, and uses. Stipes Publishing Company, Champaign, IL.

Esson, J.G. 1949. Leatherwood for early spring bloom. J. New York Bot. Gard. 50:57-59.

Graves, W.R. 2006. Distribution and reproduction of Dirca occidentalis (western leatherwood). The Four Seasons (East Bay [Berkeley, California] Regional Parks Botanic Garden) 12:54-61.

Graves, W.R. 2008. Habitat and reproduction of Dirca mexicana. Rhodora 110:365-378.

Graves, W.R., J.A. Schrader, and J. Sharma. 2006. Cold hardiness of the rare Dirca occidentalis: Comparisons to Dirca palustris from disparate provenances. J. Environ. Hort. 24:169172.

Kirkegaard, J. 1912. Trees, shrubs, vines and herbaceous perennials. The Bullard Company, Boston, MA.

McMahan, L.R. 2006. Understanding cultural reasons for the increase in both restoration efforts and gardening with native plants. Native Plants J. 7:31-34.

Nesom, G.L. and M.H. Mayfield. 1995. A new species of Dirca (Thymelaeaceae) from the Sierra of northeastern Mexico. Sida 16:459-467.

Nevling, L.I., Jr. 1964. Typification in Dirca. J. Arnold Arbor. 45:158-159.

Noshad, D., Z. Punja, and A. Riseman. 2007. Genotypic variation for resistance to Thielaviopsis basicola, the causal agent of Daphne Sudden Death Syndrome (DSDS), among Daphne taxa. HortScience 42:1639-1643.

O'Brien, E.K. and S.L. Krauss. 2010. Testing the home-site advantage in forest trees on disturbed and undisturbed sites. Rest. Ecol. 18: 359-372.

Peterson, B.J. and W.R. Graves. 2009. Variation in development and response to root-zone $\mathrm{pH}$ among seedlings of Dirca palustris (Thymelaeaceae) from three provenances. HortScience 44:1319-1322.

Peterson, B.J., W.R. Graves, and J. Sharma. 2011. Phenotypic and genotypic diversity of eastern leatherwood in five populations that span its geographic distribution. Amer. Midl. Nat. 165:1-21.

Peterson, B.J., W.R. Graves, and J. Sharma. 2009. Color of pubescence on bud scales conflicts with keys for identifying species of Dirca (Thymelaeaceae). Rhodora 111:126-130.

Repo, T., G. Zhang, A. Ryyppö, R. Rikala, and M. Vuorinen. 2000. The relation between growth cessation and frost hardening in Scots pines of different origins. Trees (Berl.) 14: 456-464.

SAS Institute Inc. 2002. SAS/STAT User's Guide. Release 9.1.3 ed. Cary, NC.

Schrader, J.A. and W.R. Graves. 2005. Seed germination of Dirca (leatherwood): Pretreatments and interspecific comparisons. HortScience 40:1838-1842.

Weng, Y.H. and W.H. Parker. 2008. Adaptive variation in fall cold hardiness of aspen from northwestern Ontario. Tree Physiol. 28:143150.

Williams, C.E. 2004. Mating system and pollination biology of the spring-flowering shrub, Dirca palustris. Plant Species Biol. 19:101106.

Wunderlin, R.P. and B.F. Hansen. 2008. Atlas of Florida vascular plants. Institute for Systematic Botany, University of South Florida, Tampa, FL. 14 Apr. 2011. <http://www.plantatlas.usf. edu/>. 